\title{
Comparison of $0.5 \%$ Ropivacaine and $0.5 \%$ Bupivacaine for Epidural Anaesthesia in Patients undergoing Lower Abdominal and Lower Extremity Surgery
}

\author{
Mohamad Ommid, M.D., Nusrat Jehan, M.D., Khairat Mohammad, M.D., Shigufta Qazi, M.D., \\ Mubasher Ahmad, M.D., Kundal Raksha, M.D. \\ Department of Anaesthesiolgy and Critical Care, Sher-i-Kashmir Institute of Medical Sciences, Soura, J\& K India.
}

\section{A B S T R A C T}

BACKGROUND: Ropivacaine, a derivative of mepivacaine like its older counterpart Bupivacaine, has recently been introduced in Indian pharmacopeia. Ropivacaine is an amide local anaesthetic but less cardiotoxic than bupivacaine.

OBJECTIVE: To compare the clinical effectiveness of ropivacaine versus bupivacaine in patients undergoing lower extremity and lowerabdominal surgeries

METHODS: 50 patients were randomized to receive $20 \mathrm{ml}$ of $0.5 \%$ ropivacaine or $0.5 \%$ bupivacaine through epidural catheter. Sensory (pinprick) and motor (bromage) measurements were made while the block was in effect, haemodynamic changes; use of additional analgesics and sedatives was noted.

RESULTS: The quality and extent of sensory and motor blockade between the two groups was comparable, although bupivacaine was found to be slightly longer acting. Both had similar motor blocking characteristics, with the exception that bupivacaine had a blockade of slightly longer duration but statistically not significant $(p>0.05)$.

CONCLUSION: Ropivacaine being lesser cardio toxic is the preferred agent for clinical epidural anaesthesia. JMS $2011 ; 14(1): 15-18$

Keywords: Anaesthesia, bupivacaine, ropivacaine, epidural catheter

Ropivacaine has recently been introduced in Indian pharmacopeia. Ropivacaine, the S-enantiomer of $\mathrm{N}$ propylpipecolic acid 2,6-xylidine, is an amide local anaesthetic that is less cardio toxic than bupivacaine. ${ }^{1}$ Like other local anaesthetics ropivacaine elicits nerve block via reversible inhibition of sodium ion influx in nerve fibres. It has lower lipid

Correspondence and reprint requests to:

Dr. Mohamad Ommid

Senior Resident,

Department of Anesthesiology \& Critical Care,

Sher-i-Kashmir Institute of Medical Sciences,

Srinagar, Kashmir (J\&K) India - 190011

Email: ommid76@yahoo.com solubility and is less likely than bupivacaine to penetrate large myelinated motor fibres. The degree of ropivacaine induced sensory and motor block are dose and age dependant. ${ }^{2,3}$ Ropivacaine presumably produces less central nervous toxicity and cardiac toxicity than bupivacaine. ${ }^{2.3}$ It blocks C-fibres faster than A fibers, but the blockade of A fibers is less with ropivacaine than a similar concentration of bupivacaine, whereas the degree of C-fibre block was similar with both drugs. ${ }^{4.5}$ The analgesic potency of ropivacaine is similar to that of bupivacaine while motor block is less pronounced and of shorter duration. ${ }^{6.7}$ This study was designed in a randomized double blind fashion to compare the clinical effectiveness of ropivacaine and bupivacaine in patients undergoing lower extremity and lower abdominal surgeries. 


\section{Material and Methods}

This study was conducted in the Department of Anesthesiology and Critical Care SKIMS, Srinagar. After explaining the whole procedure to the patients consent for the same was sought from all 50 patients, ASA patients physical status I and II patients aged 25 to 65 years were included in this double blind randomized comparative study of ropivacaine and bupivacaine. Patients were excluded if they had any contraindication to extradural anaesthesia or any significant medical history or concomitant disease which would influence postoperative assessments.

Prior to blockade patients received $500 \mathrm{ml}$ of crystalloid. Local skin infiltration was done with $2 \mathrm{ml}$ of $2 \%$ xylocaine and epidural blocks were performed in sitting position with 18 gauge Tuohy needle in L2-L3 or L3-L4 inter space. Following identification of the epidural space with the loss of resistance technique, epidural catheter was threaded in place. After giving test dose of $3 \mathrm{ml}$ of xylocaine with epinephrine 1 in $200,000(5 \mathrm{mcg} / \mathrm{ml}), 20 \mathrm{ml}$ of blinded study drug was injected over 5 minutes. Patients were immediately turned supine and block measurements initiated. Repetitive block assessments were done by two blinded observers. These measurements included bilateral upper and lower extents of anaesthesia to pinprick with a blunt 27gauge needle at $5 \mathrm{~min}$ intervals for 30 minutes and thereafter every 15 minutes for 5 hours till sensory blockade resolved. Motor blockade was noted at same intervals using bromage scale. Tourniquet pain was judged as present or absent when applicable. Heart rate and blood pressures were measured prior to administration of epidural and thereafter every $5 \mathrm{~min}$ intervals for 1 hour and every 30 minutes thereafter for 3hours following completion of block. Epidural catheter was kept in place for providing postoperative pain relief with top up doses of $5 \mathrm{ml}$ of either Bupivacaine $0.25 \%$ or $0.2 \%$ Ropivacaine. During abdominal surgeries Fentanyl in the dose of 2 microgram $/ \mathrm{kg}$ was given for visceral pain relief. Additional sedatives and analgesics required during the surgical procedures were tabulated and so were the doses of ephedrine and atropine. All the parameters were recorded and statistically evaluated using Mann-Whitney U test, chisquare and ANOVA.

\section{Results}

50 patients were included in the study, 25 patients in both the ropivacaine and bupivacaine groups. No differences were found in patient or preoperative characteristics between the two groups (Tables 1-3). The onset of sensory analgesia and peak sensory height did not differ between the two groups. In both the groups sensory blockade of the sacral dermatomes was virtually complete at $20 \mathrm{~min}$. The regression of the upper sensory was more rapid with ropivacaine and the duration of sensory block significantly longer in the bupivacaine in the T-12 to S-5 dermatomes $(p=0.001)$. Adequacy of anaesthesia and muscle relaxation on comparison between the two groups was insignificant $(p>0.05)$. The duration of motor block was slightly longer with bupivacaine. Onset of motor blockade, peak motor block bromage score and absence of tourniquet pain was insignificant
TABLE 1:Demographic characteristics in Ropivacaine and Bupivacaine groups.

\begin{tabular}{lccc} 
Variable & Ropivacaine & Bupivacaine & \\
Age (years) & $42.5 \pm 15.8$ & $40.8 \pm 15.0$ & (NS) \\
Height (cm) & $173.5 \pm 12.1$ & $174.2 \pm 7.1$ & (NS) \\
Weight (kg) & $80.0 \pm 12.4$ & $83.3 \pm 10.2$ & (NS) \\
Gender (M:F) & $16: 9$ & $18: 7$ & (NS) \\
ASA physical & & & (NS) \\
1 & 12 & 11 & \\
2 & 13 & 14 & \\
\hline
\end{tabular}

NS = Not significant

TABLE 2: Surgical cases distribution

\begin{tabular}{lcc} 
Operation & Ropivacaine & Bupivacaine \\
Groin dissection & 4 & 5 \\
Hernia repairs & 7 & 7 \\
SSG lower limbs & 6 & 7 \\
Ano genital surgeries & 8 & 6 \\
\hline Total & 25 & 25 \\
\hline
\end{tabular}

TABLE 3: Block Characteristics and Management Between the Groups

\begin{tabular}{lcc} 
Variable & Ropivacaine & Bupivacaine \\
Number of patients per site of blockade & & \\
L2-L3 & 16 & 15 \\
L3-L4 & 9 & 10 \\
Time between injection and operation (min) & $43.8 \pm 14.7$ & $49.6 \pm 25.3$ \\
Length of surgery (min) & $167 \pm 95$ & $191 \pm 68$ \\
\hline
\end{tabular}
TABLE 4: Peripheral Block Characteristics Between Ropivacaine and
Bupivacaine

$\begin{array}{lccc}\text { Variable } & \text { Ropivacaine } & \text { Bupivacaine } & p \text { value } \\ \text { Block onset and peak } & & & \\ \mathrm{T} 10^{* *} \text { (min) } & 10 \pm 6.7 & 12.3 \pm 11.2 & \text { (NS) } \\ \text { S5 (min) } & 19.5 \pm 8.5 & 18 \pm 12 & \text { (NS) } \\ \text { Peak block height* } & T 5 \pm 3 & \mathrm{~T} 5 \pm 4 & \text { (NS) } \\ \text { Time to peak Block height (min) } & 48 \pm 18 & 56 \pm 24 & \text { (NS) } \\ \text { Peak bromage motor blockscore } & 1 \pm 1 & 1 \pm 1 & \text { (NS) } \\ \text { Block regression } & & & \\ 2 \text { dermatome (min) } & 170 \pm 56 & 180 \pm 70 & \text { (NS) } \\ \text { T10*(min) } & 235 \pm 68 & 259 \pm 48 & \text { (NS) } \\ \text { No sensory block (min) } & 330 \pm 52 & 396 \pm 51 & 0.001^{* *} \\ \text { Duration of motor block (min) } & 218 \pm 54 & 275 \pm 51 & 0.02^{* *}\end{array}$

${ }^{*} \mathrm{~T}=$ Thoracic dermatome; ${ }^{* *}$ Mann Whitney U test

on comparison between the two groups.

Haemodynamic parameters; heart rate and blood pressures changes were recorded but no significant differences observed. The measurement of heart rates showed ropivacaine and 
bupivacaine at preblock values of $73 \pm 12$ and $71 \pm 13$ beats per minute. At 30 and 60 minutes post block the values were $86 \pm 11$ and $84 \pm 13$ at 30 minutes and $88 \pm 12$ and $86 \pm 11$ beats per minute at 60 minutes respectively. Systolic blood pressure measurement preblock and $30 \mathrm{~min}$ and 60 minute postblock showed ropivacaine group values of $128 \pm 18$ and $126 \pm$ $14 \mathrm{mmHg}$ preblock, $118 \pm 17$ and $115 \pm 18 \mathrm{mmHg}$ at 30 minutes and $118 \pm 16 \mathrm{mmHg}$ and $114 \pm 12 \mathrm{mmHg}$ at 60 minutes postblock respectively. Use of additional sedation, atropine and ephedrine was similar between the groups. Similarly the duration of surgical procedures was similar on comparison.

\section{Discussion}

Epidural analgesia with local anaesthetics after lower abdominal surgery is a powerful method of relieving postoperative pain, provided that the catheter is placed at the correct dermatome. ${ }^{8}$ In addition, epidural local anaesthetics may reduce gastrointestinal paralysis and postoperative nausea and vomiting by inhibition of visceral reflex activity and reduced need for perioperative opioids. ${ }^{9-12}$ Ropivacaine is the newest aminoamide local anaesthetic (LA) available for clinical use. Its development was prompted by the need for a wider safety margin while preserving the desirable pharmacodynamic properties of bupivacaine, a potent long acting aminoamide local anaesthetic with a limited safety profile (current drug therapy 2006).

Ropivacaine and bupivacaine are produced when the methyl group (-CH3) situated on the nitrogen ion of mepivacaine is replaced by a $-\mathrm{C} 3 \mathrm{H} 7$ group in the case of ropivacaine and by a butyl group - $\mathrm{C} 4 \mathrm{H} 9$ in the case of bupivacaine. Ropivacaine is a pure solution of " $\mathrm{S}$ " enantiomer, but bupivacaine is a raecemic mixture. In terms of the central nervous and cardiac systems the s-enantiomer are recognised as being less toxic than the bupivacaine. ${ }^{13}$ Ropivacaine is a well tolerated regional anaesthetic effective for surgical anaesthesia as well as the relief of postoperative and labour pain. The efficacy of ropivacaine is similar to that of bupivacaine and levobupivacaine for peripheral nerve blocks and although it might be slightly less potent than bupivacaine when administered epidurally or intrathecally, equi-effective doses have been established.

The problem of persistent motor block limits the usefulness of epidural infusions with local anaesthetics. ${ }^{14}$ although controversial, it has been claimed that ropivacaine produces comparable sensory, but less intense, motor block compared with bupivacaine. ${ }^{12,15}$ This has not been investigated in patients undergoing lower abdominal surgery.

Bupivacaine is known to provide a more intense and longer lasting surgical block than ropivacaine in similar doses and concentrations. ${ }^{16-18}$ Clinically adequate doses of ropivacaine appear to be associated with a lower incidence or grade of motor block than bupivacaine. Thus ropivacaine with its efficacy, fewer propensities for motor block and reduced potency for cns toxicity and cardiotoxicity appears to be an important option for regional anaesthesia and for the management of postoperative and labour pain. ${ }^{19}$

In a study conducted using different dosage of ropivacaine for labour analgesia, it was found that $0.2 \%$ ropivacaine produced adequate analgesia. $^{20}$

Our comparison of $0.5 \%$ ropivacaine and $0.5 \%$ bupivacaine in patients undergoing lower abdominal and lower extremity surgeries suggest that the intensity of sensory anaesthesia is not significantly different at $0.5 \%$ concentrations, but bupivacaine tends to provide slightly longer lasting sensory blockade than ropivacaine similar to other studies. ${ }^{17,18}$ The difference is consistent with the results of a study conducted by Brown et al in 1990. In a article by Akerman B et al, it has been theorized that the shorter duration is a result of the lesser lipid solubility of ropivacaine. Statistically no significant difference was seen when the motor blockade was compared in the two groups, though bupivacaine patients showed longer lasting motor blockade. This is again comparable with the study conducted by Gerhard et al 1999 when $0.2 \%$ ropivacaine was compared with $0.175 \%$ bupivacaine where it was found that despite higher concentration of ropivacaine the motor recovery was earlier than with bupivacaine. Our findings are also consistent with the findings of the studyby Brownetal.

In conclusion, since $0.5 \%$ ropivacaine produces similar sensory and motor blockade and keeping in view less toxic profile than bupivacaine, ropivacacine can be used with better margin of safety at higher concentrations for a denser sensory blockade. And motor recovery being slightly earlier so can be used safely in higher concentrations as well.

\section{References}

1. Feldman HS, Arthur GR, Covino BG. Comparative systemic toxicity of convulsant and supraconvulsant doses of intravenous ropivacaine, bupivacaine and lidocaine in the conscious dog. Anaesthesia Analgesia 1989;69:794-801.

2. Steinbrook RA. Epidural anaesthesia and gastrointestinal motility. Anaesthesia Analgesia 1998;86:837-844.

3. WiebalckA, Brodner G, Van Aken H. Postoperative patient controlled epidural analgesia; the effect of adding sufentanil to bupivacaine. Anaesthesia Analgesia 1997;85: 124-9.

4. ScottDB, Lee A, Fagan D, et al.Acute toxicity of ropivacaine compared with that of bupivacaine. Anaesthesia 1989;69: 563-9.

5. Reiz S, Haggamark S, Johansson G, Nath S. Cardiotoxicity of ropivacaine: a new amide local anaesthetic agent. Acta anaesthesiolo Scand 1989;33:93-98.

6. Thorpe JA, Parisi VM,Boylan PC, Johnston DA. The effect of continous epidural analgesia on caeseran section for dystocia in nulliparous women. American Journal of Obstetrics and Gynaecology 1989;161:670-675.

7. Mcclure JH. Ropivacaine. British Journal of Anaesthesia 1996;76:300-307. 
8. Scott DA, Beilby DS, McClymont C. Postoperative analgesia using epidural infusions of fentanyl with bupivacaine. A prospective analysis of 1104 patients. Anesthesiology 1995;83:727-37.

9. Asantila R, Eklund P, Rosenberg PH. Continuous epidural infusion of bupivacaine and morphine for postoperative analgesia after hysterectomy. Acta Anaesthesiol Scand 1991; 35:13-17

10. Wattwil M, Thoren T, Hennerdal S. Garvill JE. Epidural analgesia with bupivacaine reduces postoperative paralytic ileus after hysterectomy. Anesth Analg 1989;68:353-8.

11. Thorn SE, Wattwil M. Naslund I. Postoperative epidural morphine, but not epidural bupivacaine, delays gastric emptying on the first day after cholecystectomy. Reg Anesth 1992; 17: 9-14.

12. Scheinin B, Asantila R, Orko R. The effect of bupivacaine and morphine on pain and bowel function after colonic surgery. Acta Anaesthesiol Scand 1987;31:161-4.

13. Michel Girard. Ropivacaine and levobupivacaine; review of the adult and non obstetricsal literature. Anaesthesiology Rounds 2002;1:4.

14. Muldoon T, Milligan K, Quinn P, Connolly DC, Nilsson
$\mathrm{K}$. Comparison between extradural infusion of ropivacaine or bupivacaine for the prevention of postoperative pain after total knee arthroplasty. BrJ Anaesth 1998;80:680-1.

15. McClure JH. Ropivacaine. BrJ Anoesth 1996;76:300-7.

16. Brockway MS. Bannister J, McClure JH. McKeown D, Wildsmith JA. Comparison of extradural ropivacaine and bupivacaine. BrJ Anaesth 1991; 66:31-7.

17. Brown DL. Carpenter RL, Thompson GE. Comparison of $0.5 \%$ ropivacaine and $0.5 \%$ bupivacaine for epidural anesthesia in patients undergoing lower-extremity surgery. Anesthesiology 1990;72:633-6.

18. Kerkkamp HE, Gielen MJ, Edstrom HH. Comparison of $0.75 \%$ ropivacaine with epinephrine and $0.75 \%$ bupivacaine with epinephrine in lumbar epidural anaesthesia 1990;15:204-7.

19. Dene Simpson, Monique P Curran, Vicki Oldfield and Gillian M Keating. Ropivacaine: a review of its use in regional anaesthesia and acute pain management. Aids drugevaluation. Auckland, NewZealand.

20. Yaakov Beilin, Mihai Galea, Jeffery Zahn, Carol A Bodian. Epidural ropivacaine for the initiation of labour epidural analgesia: a dose finding study. Anaesthesia Analgesia 1999; 88:1340-5. 